Brit. J. industr. Med., 1964, 21, 78.

\title{
A RAPID METHOD FOR THE DETERMINATION OF DELTA AMINO-LAEVULINIC ACID IN URINE
}

\author{
BY \\ SHAWKIA MEHANI* \\ From the Nuffield Department of Industrial Health, King's College, \\ University of Durham, Newcastle upon Tyne
}

(RECEIVED FOR PUBLICATION MAY 17, 1963)

\begin{abstract}
A rapid colorimetric method, sensitive to $0.5 \mu \mathrm{g}$., is described for the determination of delta amino-laevulinic acid in urine. The method consists of a modification of the picrate method of Shuster in which interference by porphobilinogen is avoided by the use of an ion exchange resin. The method is found to give results which compare in accuracy with the longer standard method of Mauzerall and Granick.
\end{abstract}

In a series of papers published during the last decade, Shemin and Russell (1953) have shown that delta amino-laevulinic acid (ALA) and porphobilinogen (PBG) are intermediates in the biosynthesis of porphyrins. Recently, Kretser and Waldron (1963) have found that, in a group of workmen exposed to a lead-contaminated atmosphere, a rise in the urinary lead excretion of individuals was accompanied by an elevated urinary ALA concentration, and Haeger (1958) has pointed out that the determination of urinary ALA may prove to be a sensitive method of detecting the very early stages of lead intoxication.

In an attempt to use this test in the control of lead absorption in a group of lead smelters, the author examined the methods currently in use for the estimation of ALA. The method described by Mauzerall and Granick (1956), although sensitive, was found to require too much time to be of use for the routine estimation of a large number of urine samples. Shuster's picrate method (1956), while rapid in use, is subject to interference by urinary PBG, which is present in increased concentrations in lead and other types of porphyria.

By combining the separation of ALA from urine described by Mauzerall and Granick (1956) with Shuster's picrate method, the advantages of both methods are retained: PBG does not interfere; the reagents are few and are stable for months at room temperature; the colour developed is stable for several hours; and the overall method takes about

*Working with a grant from the United Arab Republic. one third the time of that of Mauzerall and Granick, with no loss of precision.

\section{Experimental}

Outline of the Method.-Urine containing PBG and ALA is passed through a column of Dowex 2 resin, as described by Mauzerall and Granick (1956). PBG is held on the column, while ALA is eluted and reacted with picric acid in an alkaline solution to form a colour complex which is spectrophotometrically determined.

Reagents.-The following reagents were used.

Dowex 2 Resin, 200-400 Mesh.-The ion exchange resin is shaken with water and allowed to sediment, after which the bulk of the water is sucked off. The washings are repeated until the supernatant liquid is clear. The resin is then converted to the acetate form. A column packed with the resin is washed with $3 \mathrm{M}$ sodium acetate until the eluate is chloride-free. The column is then washed with water until the washings are neutral to litmus. The prepared ion exchange resin is kept in about twice its volume of water in a covered vessel. Stored in this way it will keep for at least three to four months at room temperature.

Picric Acid.-A saturated aqueous solution of picric acid.

\section{Hydrochloric Acid $5 N$}

Sodium Hydroxide $10 \mathrm{~N}$

Apparatus.-The removal of PBG from the urine sample is carried out in a chromatographic column measuring $10 \times 1 \mathrm{~cm}$. A cotton-wool plug is placed in the bottom of the column which is then packed by sedimentation of Dowex 2 resin to a level of 2 to $3 \mathrm{~cm}$. 
A pad of filter paper is placed on top of the resin, and the column is rinsed with about $5 \mathrm{ml}$. of water before use.

Method.-If it is necessary to store the urine before analysis, ALA will keep for at least 20 days at $p \mathrm{H} 4$ to 6 and a temperature of about $4^{\circ} \mathrm{C}$.

Place exactly $1 \mathrm{ml}$. of urine on the Dowex 2 column and adjust the rate of flow to about six drops a minute. Collect the urine in a test tube. Wash the column twice with 2-ml. portions of water and collect the washings, together with the urine, in the same test tube. Add $0.1 \mathrm{ml}$. of saturated picric acid to the contents of the test tube followed by $0.2 \mathrm{ml}$. of $10 \mathrm{~N} \mathrm{NaOH}$. Shake the tube after each addition. Finally, add $1 \mathrm{ml}$. of $5 \mathrm{~N} \mathrm{HCl}$ and again mix. If the test is positive an orange colour will develop almost immediately. After 10 to 15 minutes, transfer the tube contents to a $1-\mathrm{cm}$. cuvette and measure the optical density at $450 \mathrm{~m} \mu$, using distilled water as the reference solution. Carry out a blank determination by treating $5 \mathrm{ml}$. of water in the same manner as the Dowex 2 eluate.

Standard Curve.-Prepare a stock of PBG-free urine by passing a pooled collection of normal urine samples through a column of Dowex 2 resin. Make up standard solutions of ALA $\cdot \mathrm{HCl}^{*}$ in PBG-free urine to give concentrations of from 1 to $10 \mu \mathrm{g}$. ALA $\cdot \mathrm{HCl}$ per $\mathrm{ml}$. To $1-\mathrm{ml}$. aliquots of the standard solutions, add $4 \mathrm{ml}$. of distilled water and treat the solutions for the development of colour, as described above. Measure the optical densities of the solutions in $1-\mathrm{cm}$. cuvettes at $450 \mathrm{~m} \mu$. Correct for the colour due to the ALA originally present in the urine samples by subtracting the optical density reading of the solution containing $1 \mu \mathrm{g}$. ALA $\cdot \mathrm{HCl}$ per $\mathrm{ml}$. from each subsequent reading, and plot a graph of optical density against $(n-1) \mu \mathrm{g}$. of added ALA $\cdot \mathrm{HCl}$.

\section{Calculation and Results}

Figure 1 shows the standard curve obtained when the extinctions were read in a Unicam S.P. 600 spectrophotometer at a wave-length of $450 \mathrm{~m} \mu$ using a $1 \mathrm{~cm}$. cuvette.

There is a linear relation between the colour developed and the concentration in the range from 0 to $10 \mu \mathrm{g}$. ALA $\cdot \mathrm{HCl}$ per $\mathrm{ml}$. of urine. This range covers the maximum amount of ALA expected in $1 \mathrm{ml}$. of pathological urine from lead workers, but in acute porphyria the sample may require dilution.

From the standard curve it was calculated that O.D. $450 \times 7 \cdot 82=\mu \mathrm{g}$. ALA per ml. urine.

Tables 1 and 2 show that the recovery of added ALA from normal human urine according to the rapid method varied from 90 to $108 \%$. Analyses of normal urine samples, containing known amounts of added ALA, by both the rapid method and the Mauzerall and Granick technique gave results which agreed closely (Table 2 ).

*ALA·HCl supplied by $\mathrm{K}$ and $\mathrm{K}$ Chemicals, New York, N.Y.

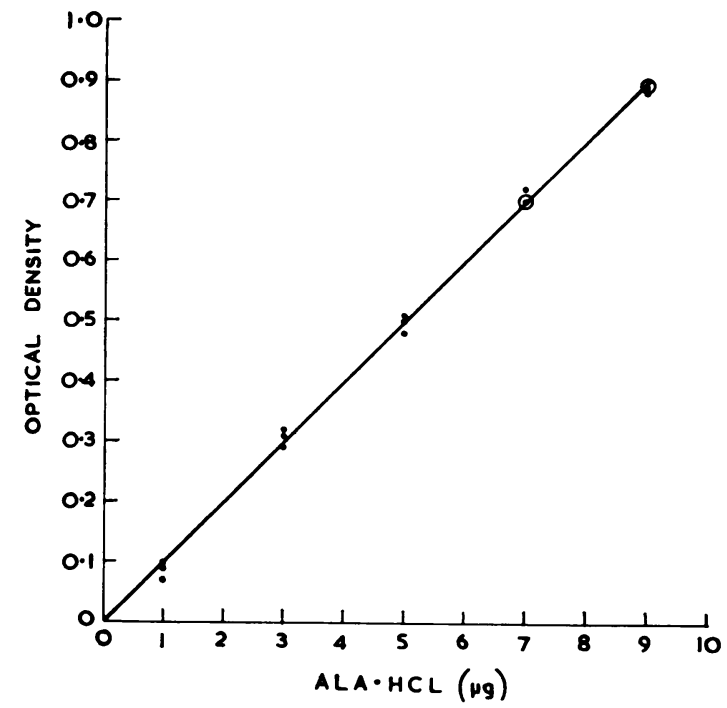

FIG. 1.-Standard curve for determination of $\delta$-ALA in human urine (optical density $450 \mathrm{~m} \mu$ ). Conversion factor of ALA. HCl to $\mathrm{ALA}=\mathbf{0 . 7 8 2}$.

TABLE 1

RECOVERY OF ADDED $\delta$-ALA FROM NORMAL HUMAN URINE BY THE RAPID METHOD

\begin{tabular}{c|c|r}
\hline ALA Added $(\mu \mathrm{g} . / \mathrm{ml})$. & ALA Recovered $(\mu \mathrm{g} . / \mathrm{ml})$. & $\%$ \\
\hline 7.04 & 6.96 & 99 \\
5.48 & 5.55 & 101 \\
3.91 & 3.91 & 100 \\
2.35 & 2.42 & 103 \\
0.78 & 0.70 & 90 \\
\hline
\end{tabular}

TABLE 2

COMPARISON BETWEEN THE RAPID METHOD AND THE MAUZERALL AND GRANICK TECHNIOUE FOR THE ESTIMATION OF $\delta$-ALA ADDED TO NORMAL HUMAN

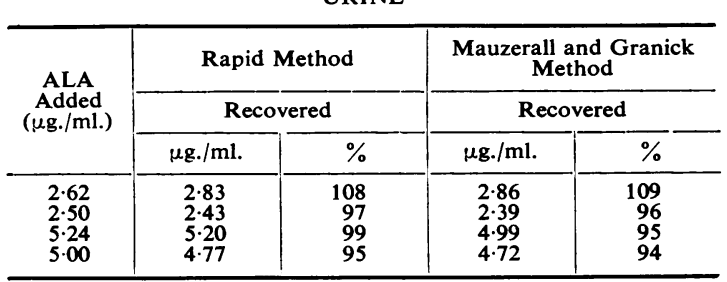

Specificity and Interfering Substances.-Urinary creatinine produces a deep orange colour with alkaline picrate (Jaffe, 1886), but the addition of hydrochloric acid in the method bleaches this colour. The picrate colour of acetone is deepened by hydrochloric acid, but the method can be used in the presence of amounts of acetone not exceeding $100 \mu \mathrm{g}$. per $\mathrm{ml}$. It was found that acetone gave no appreciable colour below this concentration (Shuster, 
1956). The colour obtained with many carbonyl compounds, such as $\alpha$-oxoglutarate, fades within 10 to 15 minutes, as contrasted with the colour from ALA, which is stable for several hours. Glycine, glucose, and succinic acid, in amounts of $10 \mathrm{mg}$., gave no appreciable colour under the conditions of the test (Shuster, 1956).

Grateful thanks are due to Professor R. C. Browne and to Dr. J. Steel for their kind supervision, to Mr. R. W. Ellis for his expert technical assistance, to Dr.
D. J. Newell and Mrs. D. Weightman for statistical help, and to the Ministry of Education of the United Arab Republic who supported this work.

\section{REFERENCES}

Haeger, B. (1958). Lancet, 2, 606.

Jaffe, M. (1886). Hoppe-Seylers Z. physiol. Chem., 10, 391.

Kretser, A. J. de, and Waldron, H. A. (1963). Brit. J. industr. Med., 20,35 .

Mauzerall, D., and Granick, S. (1956). J. biol. Chem., 219, 435.

Shemin, D., and Russell, C. S. (1953). J. Amer. Chem. Soc., 75, 4873.

Shuster, L. (1956). Biochem. J., 64, 101.

\section{THE OCTOBER (1963) ISSUE}

The October (1963) issue contains the following papers:-

The Successful Prevention of Silicosis among China Biscuit Workers in the North Staffordshire Potteries. A. MeIKLEJohn

Aluminium Pneumoconiosis. I. In vitro Comparison of Stamped Aluminium Powders Containing Different Lubricating Agents and a Granular Aluminium Powder. B. CoRrIN

Aluminium Pneumoconiosis. II. Effect on the Rat Lung of Intratracheal Injections of Stamped Aluminium Powders Containing Different Lubricating Agents and of a Granular Aluminium Powder. B. CorrIN

Energy Expenditure Ranges and Muscular Work Grades. J. R. BRown and G. P. Crowden

The Control of Operating-suite Temperatures. F. P. ElLIS

Effect of Dust Suppression Measures on the Prevalence of Coal-workers' Pneumoconiosis in the Dutch Coalmines. Ch. A. M. Hendriks and H. Claus

A Comparison of Some Alternative Procedures in the Classification of Chest Radiographs for Coal-workers' Pneumoconiosis. S. Rae, J. R. Ashford, D. C. Morgan, R. S. H. Pasqual, and N. G. Pearson

An Experiment in Film Reading. F. D. K. LIDDELL

A Follow-up Study of Lead Workers. I. Dingwall-Fordyce and R. E. LANE

The Mechanical Fragility of the Red Cell in Patients with Lead Poisoning. A. J. de Kretser and H. A. WALDRON

Byssinosis Prevalence and Flax Processing. A. Bouhuys, F. Hartogensis, and H. J. H. Korfage

Blood Groups of Miners with Coal-workers' Pneumoconiosis and Bronchitis. I. T. T. Higgins, P. D. OldhAM, G. S. Kilpatrick, R. J. Drummond, and B. Bevan

Book Reviews

Index to Volume 20

A number of copies are still available and may be obtained from the Publishing Manager, British Medical Association, Tavistock Square, W.C.1. price 18s. $6 d$. 